BONPLANDIA 20(2). 2011

ISSN: 0524-0476

\title{
CONOCIMIENTO Y UTILIZACIÓN DE PLANTAS MEDICINALES POR POBLADORES RURALES DEL BOSQUE CHAQUEÑO SERRANO DE CÓRDOBA (ARGENTINA)
}

\author{
VIOLETA FURLAN ${ }^{1,2}$, CAROLINA TORRES ${ }^{2}$ \& LEONARDO GALETTO²
}

\begin{abstract}
Summary: Furlan, V., C. Torres \& L. Galetto. 2011. Knowledge and utilization of medicinal plants by rural inhabitants of the Chaco Serrano Forest in Córdoba (Argentina). Bonplandia 20(2): 285-307.
\end{abstract}

\begin{abstract}
The objective of this study is to compare the knowledge and utilization of medicinal plants by rural people from Chaco Serrano of Córdoba (Argentina), considering: a) the conservation status of the study sites (two of them near from natural protected areas (NPA) and other two located far away from NPA), b) the availability of plant species from each site. To achieve these aims we complemented quantitative (sampling and ecological indexes applied to ethnobotany) and qualitative methodology (ethnographic approach). The results show that: a) the diversity of plants surveyed in the field and known by the locals, assessed with different indices, do not show major differences between sites; b) knowledge and use of native medicinal species are not related to the vicinity to NPA; c) the main diseases treated at the four sites are of digestive, respiratory and circulatory systems. In conclusion, the proximity of NPA (greater access to native species) and /or environmental availability of plant resources do not seem to be the main factors influencing the knowledge on medicinal plants among rural people. Nevertheless, the constant exchange of knowledge and species among the informants and the sources of knowledge would be some of the important factors that might influence the use and knowledge of medicinal plants in the study region.
\end{abstract}

Key words: Ethnobotany, popular knowledge, plant resource availability, natural protected areas.

Resumen: Furlan, V., C. Torres \& L. Galetto. 2011. Conocimiento y utilización de plantas medicinales por pobladores rurales del Bosque Chaqueño Serrano de Córdoba (Argentina). Bonplandia 20(2): 285-307.

El objetivo del trabajo es comparar el conocimiento y utilización de plantas medicinales por pobladores rurales del Bosque Chaqueño Serrano de Córdoba (Argentina), considerando: a) el estatus de protección de los sitios de estudio (dos sitios próximos a áreas naturales protegidas (ANP) y dos sitios alejados de las mismas), b) la disponibilidad vegetal en cada sitio. Se complementaron metodologías cuantitativas (muestreos e índices ecológicos aplicados a la etnobotánica) y cualitativas (enfoque etnográfico). Los resultados muestran que: a) la diversidad de especies relevadas y la diversidad de especies conocidas por los pobladores, no muestran diferencias significativas entre sitios; b) los conocimientos y utilización de especies medicinales nativas no se relacionan con la cercanía a ANP; c) las principales afecciones tratadas con plantas medicinales en los cuatro sitios estudiados son de tipo digestivas, respiratorias y circulatorias. La cercanía a un ANP (mayor accesibilidad a especies nativas)

\footnotetext{
${ }^{1}$ Museo de Antropología, Universidad Nacional de Córdoba. Av. Hipólito Yrigoyen 174. CP (5000), Córdoba.

${ }^{2}$ Instituto Multidisciplinario de Biología Vegetal, Universidad Nacional de Córdoba-Consejo Nacional de Investigaciones Científicas y Técnicas. Av. Vélez Sarsfield 1611, Ciudad Universitaria, CPX5016GCA, Córdoba.
} 
y/o disponibilidad ambiental de recursos vegetales no serían los principales factores que influyen en los conocimientos sobre plantas medicinales entre los pobladores rurales. Sin embargo, tanto el intercambio constante de saberes y de especies entre los informantes como las distintas fuentes de conocimiento podrían ser algunos de los factores influyentes en la utilización y conocimiento de las plantas medicinales en la región de estudio.

Palabras clave: Etnobotánica, conocimiento popular, disponibilidad de recursos vegetales, áreas naturales protegidas.

\section{Introducción}

La utilización de plantas silvestres como medicina o alimento forma parte del conocimiento ecológico tradicional (CET), siendo una práctica que se desarrolla en diferentes culturas a lo largo de la historia de la humanidad (Caballero, 1986). Esta relación hombre-planta está determinada por un abanico de factores, como el contexto socioecológico y la disponibilidad de recursos vegetales presentes en los sitios de asentamiento de las comunidades humanas. También, los usos y significados que poseen las plantas pueden depender de factores socio-económicos, de la cultura de los sujetos y de las interrelaciones que ellos mantengan o hayan tenido con otras comunidades (Martínez \& Fierro, 2001; Arias Toledo, 2008). La relación entre los seres humanos y su entorno biológico varía en el espacio y en el tiempo como resultado de la compleja interacción entre factores biológicos, ambientales, sociales y culturales (Caballero \& Cortés, 2001; Arias Toledo \& al., 2007a; Arias Toledo, 2008). Por lo tanto, esta relación que mantiene cada cultura con el entorno natural, en general, y con las plantas en particular, tiene características específicas que deben ser consideradas para cada situación particular.

La provincia de Córdoba presenta una gran diversidad de especies vegetales con valor medicinal (Barboza \& al., 2006). Particularmente el distrito fitogeográfico del Chaco Serrano (Cabrera, 1976) es uno de los de mayor riqueza en cuanto a plantas de interés etnobotánico (Arias Toledo, 2006, 2008; Menseguez\& al., 2007; Trillo \& al., 2007, 2010), donde su recolección y utilización se encuentra muy extendida en áreas rurales (Martínez, 2005). El bosque serrano presenta diferentes estados de conservación, relacionados con la intensidad y tipo de actividades que en él se realicen. El paisaje actual está representado por un mosaico formado por manchones de bosque de especies nativas, manchones de bosque compuesto por especies nativas y exóticas, junto con fachinales y pastizales de sustitución (Zak \& al., 2004).

$\mathrm{Si}$ consideramos que existen relaciones entre el entorno y el conocimiento sobre plantas que tienen los pobladores de un determinado sitio, es posible que se puedan detectar diferencias en el conocimiento botánico comparando poblaciones con mayor o menor accesibilidad a las plantas silvestres. Teniendo en cuenta esta perspectiva, se plantea la presente investigación sobre el conocimiento y usos de plantas medicinales que poseen y realizan los pobladores rurales de sitios cercanos y lejanos a áreas naturales protegidas (ANP) del Chaco Serrano de Córdoba. Con este fin, se analizó la diversidad de plantas medicinales presentes en cada sitio de estudio en relación al conocimiento que tienen los pobladores; se discriminó conocimiento y utilización de plantas nativas y exóticas, y se analizaron los diferentes usos que los pobladores efectúan.

Bajo el supuesto de que la diversidad de plantas conocidas y usadas por las poblaciones humanas puede ser afectada por la diversidad de plantas presentes en el ambiente (Hanazaki $\&$ al., 2000), se espera que la cercanía de los pobladores a ANP se relacione con un mayor conocimiento y utilización de plantas medicinales por una mayor disponibilidad ambiental de posibles recursos vegetales.

\section{Área de estudio}

Se tomaron como unidades de estudio sitios de bosque en cuatro localidades cercanas a la ciudad de Córdoba, dos próximas a ANP: La Rancherita (Departamento Santa María) y Los Manantiales (Departamento Colón) y dos alejadas: Estancia Santo Domingo 
(Departamento Colón) y Falda del Carmen (Departamento Santa María).

Las localidades de La Rancherita y Los Manantiales pueden ser consideradas como áreas de bosque continuo para la escala del trabajo que abordamos y están incluidas dentro de ANP de dominio comunal. Mientras que, tanto en Falda del Carmen como en Santo Domingo, el bosque se encuentra representado por fragmentos rodeados por una matriz en la cual se realizan actividades agropecuarias. En la Tabla 1 se presenta una descripción detallada de las características de las cuatro comunidades estudiadas. Se puede destacar que ninguna de las localidades tiene escuela, los niños viajan diariamente a localidades cercanas para cumplir con los ciclos de EGB 1 y 2. Tanto en la Rancherita como en Falda del Carmen la población varía mucho durante la temporada estival por afluencia de turismo nacional, en estos momentos llega a duplicarse el número estable de habitantes que se menciona en la Tabla 1. Las principales fuentes de trabajo en La Rancherita están relacionadas con el turismo y empleo público en la comuna. Dentro de los empleos relacionados con el turismo se brinda alojamiento, servicio de empleada doméstica y oferta de productos regionales (pan casero, pastelitos, dulces y "yuyos" para el mate). Falda del Carmen, en cambio, no presenta una infraestructura particular dedicada al turismo, los turistas generalmente poseen casas de veraneo o las alquilan. A diferencia del resto de los sitios, el área de Los Manantiales presenta una ONG muy activa, conformada por la mayor parte de los adultos del área entre los que se destacan académicos, científicos y "ambientalistas" que viven o trabajan en la zona. Esta institución se encarga de movilizar a la comunidad en pos de una forma de vida "amigable con la naturaleza" realizando talleres de formación e informando a los turistas sobre las prácticas en la reserva. El proyecto de mayor porte que han llevado a cabo es la formación de la Reserva Los Manantiales, que sirve de corredor biológico entre la Reserva "Los Quebrachitos" y la Reserva Hídrica Natural Parque La Quebrada. Por su parte, la Estancia Santo Domingo presenta un fuerte contraste en el modo de vida de quienes trabajan en la estancia y los productores que la rodean. Dentro de la estancia viven 15 trabajadores, en su mayoría foráneos, quienes administran este lugar no viven en la zona, viajan diariamente hasta el área. Fuera de la estancia los pobladores son en su mayoría locales y trabajan en producción orgánica con mano de obra familiar. Tanto en esta zona como en Falda del Carmen, no se contrata mano de obra extra en ningún momento del año.

Tabla 1. Caracterización de los sitios de estudio. Datos obtenidos a partir del censo 2001 (INDEC, 2001) y complementados a través de entrevistas a jefes comunales y personal a cargo de cada sitio. El número de habitantes señalado entre paréntesis corresponde al mencionado por los jefes comunales para el predio en estudio. Los usos mencionados están ordenados de mayor a menor según la frecuencia de actividades desarrolladas.

\begin{tabular}{|c|c|c|c|c|}
\hline $\begin{array}{c}\text { Características de las } \\
\text { comunidades }\end{array}$ & & $\begin{array}{c}\text { Nro. de } \\
\text { Habitantes }\end{array}$ & $\begin{array}{c}\text { Área reserva } \\
\text { /predio (ha) }\end{array}$ & Usos \\
\hline \multirow[t]{2}{*}{ Cercanas a ANP } & La Rancherita & 53 & 35 & $\begin{array}{l}\text { recreativo, científico, } \\
\text { recolección de especies } \\
\text { medicinales }\end{array}$ \\
\hline & Los Manantiales & 40 (15 familias) & 1200 & $\begin{array}{l}\text { recolección de leña y } \\
\text { especies medicinales, cría } \\
\text { de ganado, recreativo, } \\
\text { científico }\end{array}$ \\
\hline \multirow[t]{2}{*}{ Lejanas a ANP } & $\begin{array}{l}\text { Estancia Santo } \\
\text { Domingo }\end{array}$ & 17 familias & 5600 & $\begin{array}{l}\text { producción agropecuaria } \\
\text { con tecnología de avanzada, } \\
\text { producción orgánica (fuera } \\
\text { de la estancia) }\end{array}$ \\
\hline & Falda del Carmen & 183 (8 familias) & 45 & $\begin{array}{l}\text { producción hortícola y } \\
\text { frutícola a escala familiar }\end{array}$ \\
\hline
\end{tabular}




\section{Metodología}

El relevamiento de datos se realizó entre los meses de febrero y diciembre de 2008. Para esta investigación, se utilizaron metodologías tanto cualitativas como cuantitativas en pos de lograr una complementariedad de aproximaciones. Se utilizó información cuantitativa obtenida a partir de relevamientos florísticos e información cualitativa obtenida por medio de entrevistas a informantes clave de cada localidad. Conjuntamente, se realizaron caminatas con los entrevistados en los fragmentos de bosque o zonas circundantes a las viviendas para identificar, a campo, las especies utilizadas, recolectándose aquéllas que presentaban dudas sobre su identidad taxonómica, para su posterior identificación. Además, las caminatas con los entrevistados brindaron una nueva oportunidad para registrar los usos y conocimientos asociados a las plantas reconocidas en el trayecto.

A partir de relevamientos florísticos, se estimó la riqueza y abundancia de las especies medicinales encontradas. Para ello se realizaron cuatro transectas de faja de $2 \mathrm{~m}$ de ancho por $10 \mathrm{~m}$ de largo por sitio de muestreo. Para determinar las especies medicinales con usos registrados, disponibles como recursos, se empleó bibliografía pertinente, en particular, el listado de plantas medicinales de la Argentina de Barboza \& al. (2009).

Para recabar información cualitativa del conocimiento botánico local sobre plantas medicinales, se aplicó un enfoque etnográfico. Las entrevistas fueron de tipo semiestructuradas, con preguntas iniciales abiertas y amplias para que el entrevistado desarrolle su respuesta apelando a sus propias categorías (Guber, 1991; Taylor \& Bogdan, 1987; Arias Toledo $\&$ al., 2007a). A través de esta metodología, se intentó rescatar las clasificaciones y categorías de los propios sujetos sin imponer el orden de categorización del investigador. De esta manera, se pretende recuperar los saberes locales y dar lugar a lo imprevisto, aquello que va más allá de lo esperado por el investigador. Desde esta perspectiva teórica, se entrevistó a los informantes clave de cada sitio. Con el objeto de seleccionar los informantes clave, se utilizó la técnica de "snow ball" o "bola de nieve". Se realizó una primera visita a cada población para contactar a diferentes personas de la localidad y que ellas recomienden al más idóneo en la temática. Se realizaron entre cuatro y seis visitas en cada uno de los sitios de estudio con el objetivo de familiarizarse con la comunidad y conseguir entrevistar a todos los informantes. Las entrevistas se realizaron siguiendo las recomendaciones propuestas por Albuquerque $\&$ al. (2008).

Para cada una de las especies medicinales mencionadas por los pobladores se preguntó acerca de su uso efectivo, con qué fin se utilizaba cada una y si podían reconocerlas en el terreno. Para hacer la estimación de la diversidad de conocimientos en cada población, se tomó cada una de las menciones de las diferentes especies como expresión de frecuencia de uso ("abundancia"). El número de entrevistas realizado se determinó de acuerdo a la cantidad de informantes clave de cada sitio. Tanto en La Rancherita como en Los Manantiales se realizaron ocho entrevistas, mientras que en Santo Domingo y Falda del Carmen se realizaron cuatro. En todos los casos, los informantes fueron, en su mayoría, mujeres $(62,5-75 \%)$ de cuarenta años en adelante y de, por lo menos, 15 años de permanencia en el sitio. Las entrevistas fueron grabadas, respetándose el relato en la trascripción de cada una de ellas.

Se realizaron listas de especies por sitio de estudio donde se describe: familia botánica, nombre científico de la especie, nombres vulgares, usos (tal como los informantes los mencionaron) y forma de preparación, cuando fue explicitada (Anexo I).

Para llevar a cabo el primer objetivo, se estimó, a través del índice de Shannon, la diversidad de especies vegetales en los relevamientos florísticos y en los registros de especies conocidas por los pobladores. Este índice se calcula como $\mathrm{H}=-\sum$ pi. $\log$ pi siendo "pi" = abundancia proporcional de cada especie.

En segundo lugar, para comparar la composición de especies vegetales entre relevamientos florísticos y las especies conocidas por los pobladores, así como las especies conocidas en los diferentes sitios, se utilizó el índice de Similitud de Jaccard de acuerdo a la fórmula: Jaccard ISI $=(\mathrm{c} / \mathrm{a}+\mathrm{b}+\mathrm{c}) \cdot 100$, donde "c" es el nro. de especies comunes entre dos 
comunidades, "a" el nro. de especies únicas presentes en la comunidad A y "b" el nro. de especies únicas presentes en la comunidad $\mathrm{B}$.

La composición de especies medicinales registrada en los relevamientos florísticos y en las entrevistas a los pobladores se analizó, además, utilizando curvas de rango-abundancia para lograr una mejor interpretación de los resultados, de acuerdo a la metodología propuesta por Feinsinger (2003). Estas curvas representan la abundancia de cada una de las especies como un logaritmo en base 10 de su abundancia proporcional $(\mathrm{Pi})$, donde $\mathrm{Pi}=\mathrm{n} / \mathrm{N}$ siendo " $n$ " la abundancia de una especie y "N" la sumatoria de las abundancias de todas las especies del sitio.

Para analizar el uso que realizan los pobladores de las especies medicinales, se realizaron preguntas referentes a esta temática durante las entrevistas. Los datos se resumieron en tablas y figuras para su mejor interpretación.

Para clasificar las especies como nativas o exóticas, así como para corroborar los nombres científicos, se utilizó la Flora del Conosur del Instituto de Botánica Darwinion. Tanto las especies mencionadas como útiles como las relevadas en los relevamientos florísticos, fueron colectadas, herborizadas, identificadas y depositadas en el Herbario CORD, Universidad Nacional de Córdoba.

\section{Resultados}

Se obtuvo un listado de especies medicinales conocidas por los pobladores, de número variable según los distintos sitios (rango $=52-$ 108 especies). Del total de especies medicinales conocidas por los pobladores en cada sitio, entre el 61 y $67 \%$ de las especies son utilizadas, independientemente de si las comunidades se encuentran cercanas o lejanas a ANP (Tabla 2). Es interesante destacar que el número de especies medicinales relevadas a campo en $\mathrm{La}$ Rancherita, Los Manantiales y Santo Domingo es menor a la cantidad de especies conocidas por los pobladores. Esta tendencia es inversa en Falda del Carmen (Tabla 2).

\section{Análisis de la diversidad de conocimientos entre sitios}

En la Tabla 3 se presentan los índices de diversidad de especies relevadas y de especies conocidas por los pobladores en cada sitio. Se observa que la diversidad de especies conocidas por los pobladores es similar a la diversidad de especies relevadas a campo, presentándose una mayor diferencia en Los Manantiales.

Sin embargo, la composición de especies relevadas a campo es diferente a la composición de especies conocidas en cada sitio. Al analizar las curvas de rango-abundancia para La Rancherita se observa que Dichondra microcalyx es la especie que presenta mayor abundancia en el terreno (Fig. 1A, izquierda, punto 1). Por otro lado, la especie con mayor cantidad de menciones (6) y uso efectivo es Aloe saponaria (Fig. 1A, derecha, punto 1), utilizada principalmente como cicatrizante. Siguen en cantidad de menciones las especies Schkuhria pinnata ("canchalagua", con propiedades de protector hepático según los informantes), Achyrocline satureoides ("vira vira", "marcela", utilizada para resfríos y afecciones de las vías respiratorias), Equisetum giganteum ("cola de caballo", se utiliza "para

Tabla 2. Número de especies medicinales conocidas y efectivamente utilizadas en cada sitio de estudio. Los datos de especies conocidas y utilizadas por los pobladores se obtuvieron a partir de entrevistas. Los datos de especies relevadas se obtuvieron a partir de censos de vegetación.

\begin{tabular}{llccc}
\hline $\begin{array}{c}\text { Número de especies medicinales } \\
\text { conocidas y relevadas }\end{array}$ & La Rancherita & $\begin{array}{c}\text { Especies } \\
\text { conocidas }\end{array}$ & $\begin{array}{c}\text { Especies } \\
\text { utilizadas }\end{array}$ & Especies relevadas \\
\hline Sitios cercanos a ANP & Los Manantiales & 59 & 36 & 52 \\
\multirow{2}{*}{ Sitios lejanos a ANP } & Estancia Santo Domingo & 70 & 67 & 53 \\
& Falda del Carmen & 52 & 35 & 60 \\
\hline
\end{tabular}


Tabla 3. Valores de diversidad (índice de Shannon) de las especies relevadas a campo y conocidas por los pobladores en cada sitio de estudio en el bosque Chaqueño Serrano de Córdoba.

\begin{tabular}{llcc}
\hline Índice de Shannon & & Especies relevadas & Especies conocidas \\
\hline Sitios cercanos a ANP & La Rancherita & 1,09 & 1,7 \\
& Los Manantiales & 0,93 & 1,92 \\
\multirow{2}{*}{ Sitios lejanos a ANP } & Estancia Santo Domingo & 1,47 & 1,79 \\
& Falda del Carmen & 1,6 & 1,68 \\
\hline
\end{tabular}

los riñones") y Usnea spp. ("barba de piedra", cuyo uso está muy difundido para "curar úlceras internas y externas"). Ninguna de estas especies se registró durante el relevamiento florístico. Sin embargo, los informantes no las consideran "difíciles de conseguir".

En Los Manantiales, la curva de especies conocidas (Fig. 1B, derecha) presenta una gran cantidad de especies que son mencionadas sólo por un informante y que se pueden visualizar como la serie de puntos, hacia la derecha del gráfico, que identifican las especies poco conocidas. Esta característica se repite para todos los gráficos correspondientes a las especies conocidas (Fig. 1B, Fig. 2A, 2B). Las especies con mayor frecuencia de menciones (7) están representadas por los puntos 1, 2, 3, 4, 5, 6, 7 y 8 (Fig. 1B, derecha) y son Baccharis crispa ("carqueja", para afecciones hepáticas), Equisetum giganteum, Plantago major ("llantén", "llantel", utilizado para úlceras y gastritis), Minthostachys mollis, ("peperina", usada en el mate como digestiva). Entre ellas se incluye el liquen Usnea barbata ya que los informantes identifican a esta especie dentro de la categoría "planta" y refieren a su uso como habitual. Según la información brindada es utilizado en infusión para afecciones de la boca y garganta y como "antibiótico natural". Otras plantas frecuentemente mencionadas fueron Mentha spp. ("menta", digestivo y sedante), Urtica urens ("ortiga", depuradora de la sangre y para detener la caída del cabello) y Dysphania ambrosioides ("paico", digestiva) con seis menciones cada una. Las especies más abundantes en los relevamientos de vegetación son Dichondra sericea, Lantana camara y Sida rhombifolia representadas en las figuras por los puntos 1,2 y 3 , respectivamente (Fig. 1B, izquierda).

En el caso de la Estancia Santo Domingo, las especies más abundantes en los relevamientos de vegetación fueron Dichondra microcalyx, Cestrum parqui, Bidens subalternans, representadas por los tres primeros puntos de la curva de rango- abundancia para esta área (Fig. 2A, izquierda). Las especies con mayor cantidad de menciones (Fig. 2A, derecha) fueron Minthostachys mollis y Aloe saponaria. En esta localidad, Aloe saponaria recibe por todos los informantes la denominación de "buena para todo". Otras especies frecuentemente mencionadas fueron Geoffroea decorticans ("chañar", para afecciones de las vías respiratorias), Baccharis crispa, Aloysia citriodora ("cedrón", utilizada para ayudar al buen funcionamiento del corazón), Passiflora caerulea ("pasionaria", utilizada en infusión como sedante), Marrubium vulgare ("yerba del sapo", utilizada para prevención del cáncer) y por último Dysphania ambrosioides (digestiva; al igual que otras especies menos citadas como Aloysia gratissima, "palo amarillo"; Lippia turbinata, "poleo"; Salvia officinalis, "salvia" y Mentha x rotundifolia, "yerba buena").

Finalmente, al observar las curvas de rangoabundancia para el sitio Falda del Carmen (Fig. 2B), se visualiza una clara diferencia entre el número de especies con propiedades medicinales registradas en los relevamientos y las conocidas por los pobladores. Las especies más abundantes en los relevamientos de vegetación son Tillandsia capillaris, Bidens subalternans, Eupatorium argentinum e Iresine diffusa, representadas por los puntos 1, 2, 3 y 4 respectivamente (Fig. 2B, izquierda). Estas especies, no son reconocidas por los informantes como medicinales. Sin embargo, las especies frecuentemente mencionadas coinciden en su gran mayoría con lo descrito para los otros sitios (Fig. 2B, derecha). En este segundo grupo de especies se mencionó a Geoffroea decorticans, 

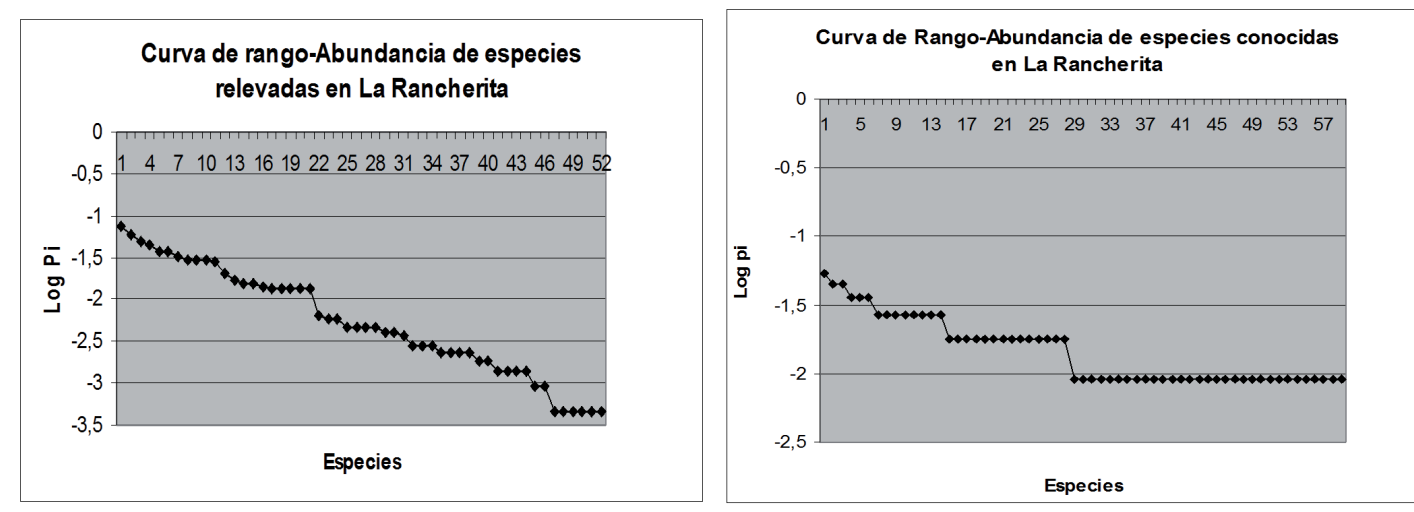

$1 \mathrm{~A}$
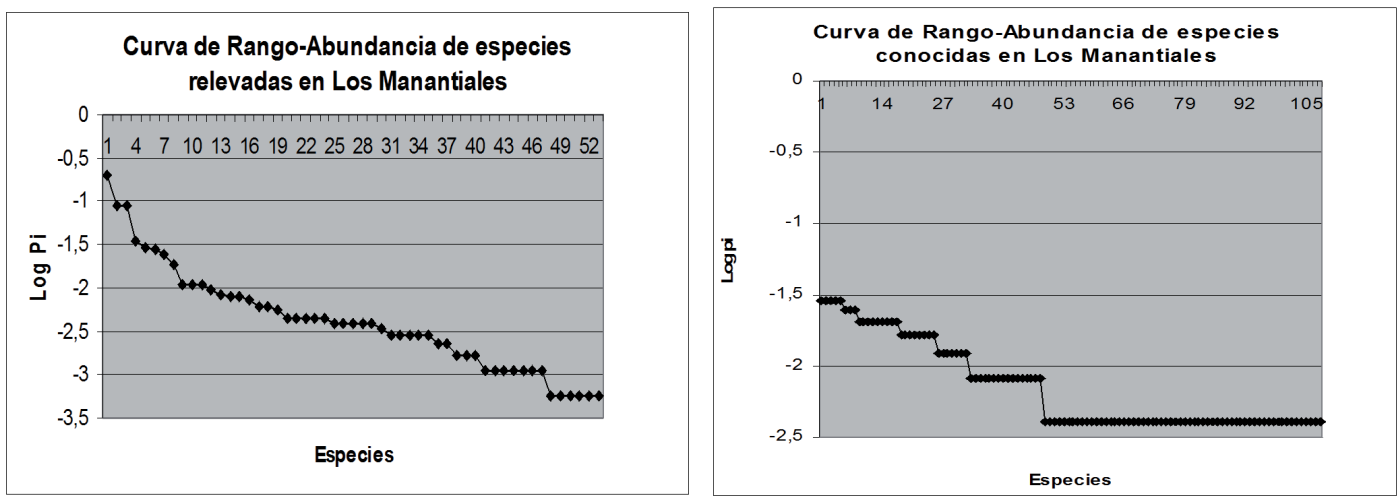

1B

Fig. 1. Curvas de Rango-Abundancia correspondientes a sitios cercanos a áreas naturales protegidas del Bosque Chaqueño Serrano de Córdoba, Argentina. Para cada sitio se presentan dos curvas: sobre la izquierda, aquellas con los datos de relevamientos de vegetación; a la derecha, aquellas con los datos de especies conocidas por los pobladores rurales. 1A: La Rancherita 1B: Los Manantiales.

Equisetum giganteum Aloysia gratissima, Lippia turbinata, Urtica urens y Ruta graveolens ("ruda", utilizada para combatir los resfríos en forma de infusión). Representadas por los puntos 1, 2, 3, 4, 5 y 6 respectivamente.

En resumen, en todos los sitios, las especies potencialmente medicinales que fueron más abundantes en los relevamientos de vegetación no fueron reconocidas como medicinales por los informantes.

\section{Análisis de similitud entre especies conocidas y especies disponibles en el campo}

La similitud entre especies relevadas a campo y las conocidas por los informantes es baja para todos los casos, sin importar la cercanía a
ANP (Tabla 4). Es importante destacar que las especies comunes entre los relevamientos de vegetación y las conocidas por los informantes son en todos los casos especies nativas (excepto Arctium minus, de origen exótico, presente en ambos relevamientos para el sitio Santo Domingo). Además se realizaron comparaciones de similitud de especies conocidas entre sitios. Se compararon sitios cercanos y lejanos a ANP entre sí y, además, los dos grupos de sitios (i.e., lejanos versus cercanos a ANP). Los valores de similitud resultaron en todos los casos entre 27 y $32 \%$.

\section{Estatus de las especies conocidas y utilizadas en los sitios de estudio}

En los sitios La Rancherita y Falda del 


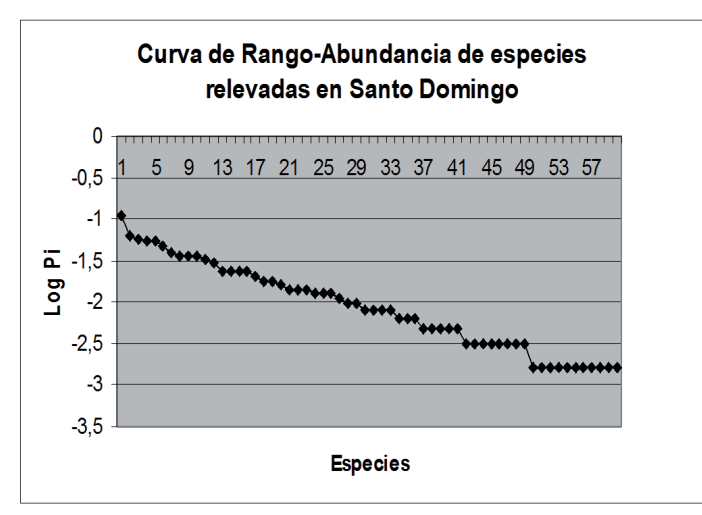

$2 \mathrm{~A}$

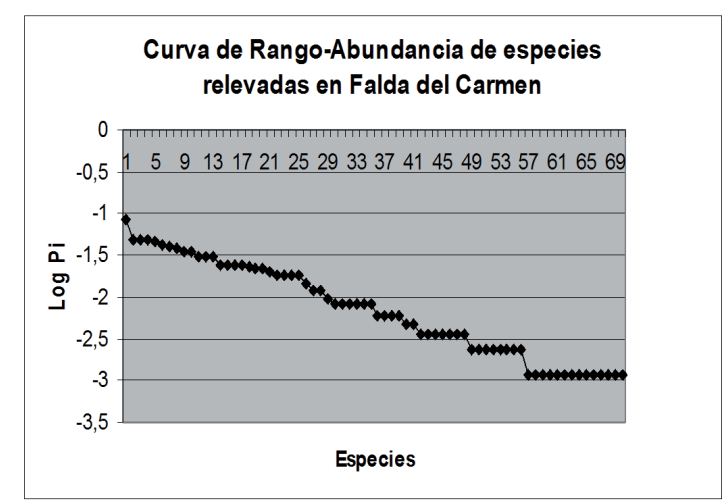

$2 \mathrm{~B}$

Fig. 2. Curvas de Rango-Abundancia correspondientes a sitios alejados de áreas naturales protegidas del Bosque Chaqueño Serrano de Córdoba, Argentina. Para cada sitio se presentan dos curvas: sobre la izquierda, aquellas con los datos de relevamientos de vegetación; a la derecha, aquellas con los datos de especies conocidas por los pobladores rurales. 2A: Santo Domingo 2B: Falda del Carmen.

Carmen más del 50\% de las especies conocidas son nativas (62,7 y $65,4 \%$ respectivamente). En contraposición, en los sitios Los Manantiales y Estancia Santo Domingo los mayores porcentajes de especies conocidas son para aquellas de origen exótico $(53,7 \mathrm{y}$ $55,7 \%$ respectivamente). Cuando se analizan los datos para las especies efectivamente utilizadas, se observa una correspondencia con los porcentajes de especies conocidas, siendo en su mayor parte especies nativas para los sitios La Rancherita (58,3\%) y Falda del Carmen $(65,7 \%)$ y exóticas para los sitios Los Manantiales $(52,2 \%)$ y Estancia Santo Domingo (53,3\%). A diferencia de lo esperado, los conocimientos y la utilización de especies medicinales nativas no están más ligados a las comunidades cercanas a ANP, pese a que estas
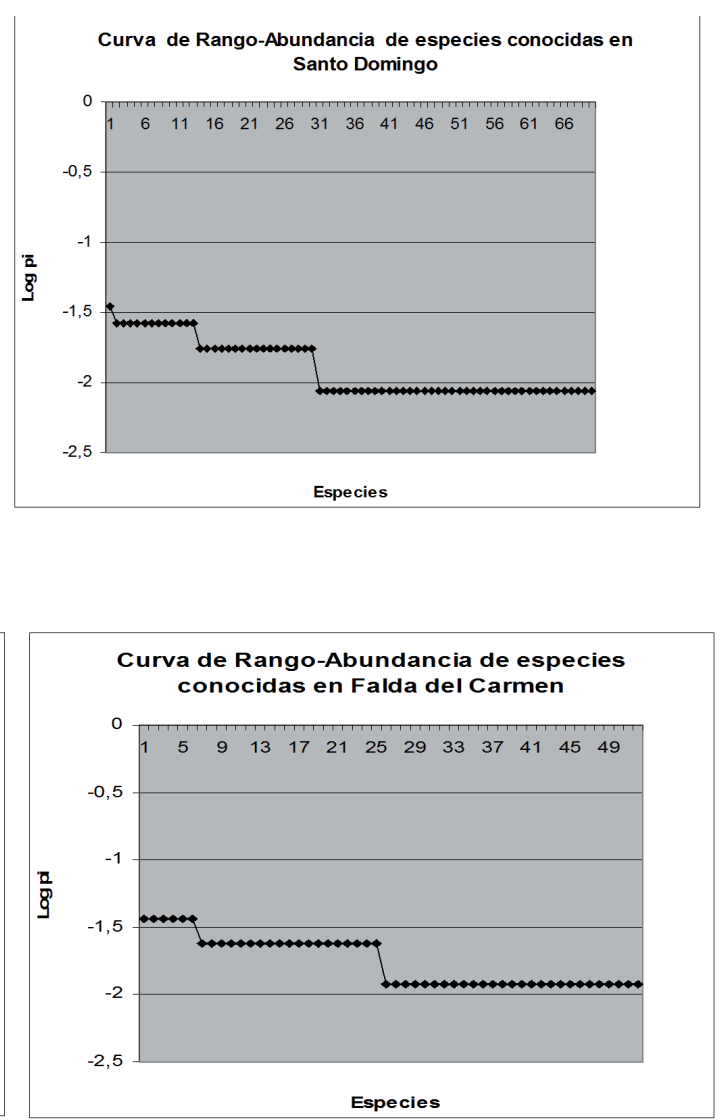

comunidades presentan mayor accesibilidad a especies nativas presentes en los fragmentos de bosque.

Se analizó también el estatus de las especies con mayor frecuencia de menciones para cada sitio. En todos los sitios más del $60 \%$ de las especies más conocidas son nativas. Los porcentajes varían desde un $62,5 \%$ en Los Manantiales, pasando por un $66,67 \%$ en Santo Domingo y Falda del Carmen hasta el máximo porcentaje (80\%) en La Rancherita.

\section{Principales usos de las especies conocidas por los pobladores}

Se realizó un análisis de los principales usos de las especies medicinales conocidas y efectivamente utilizadas en cada uno de los 
Tabla 4. Similitud entre especies conocidas y especies relevadas en los sitios cercanos y lejanos a ANP en el Bosque Chaqueño Serrano de Córdoba, Argentina. Los valores muestran el índice de similitud de Jaccard para las comparaciones entre especies conocidas y relevadas a campo en cada uno de los sitios de estudio.

\begin{tabular}{lll}
\hline \multicolumn{3}{c}{ Índice de Similitud de Jaccard (\%) } \\
\hline Sitios cercanos ANP & La Rancherita & 8,82 \\
& Los Manantiales & 5,92 \\
Sitios lejanos ANP & Estancia Santo & 7,44 \\
& Domingo & \\
& Falda Del Carmen & 12,96 \\
\hline
\end{tabular}

sitios, con el objetivo de ver qué afecciones son tratadas a través de ellas. Con este fin, se establecieron categorías que agrupan diferentes usos relacionados con afecciones de un sistema del organismo en particular, como pueden ser las categorías de afecciones del sistema digestivo, respiratorio, etc. También se establecieron categorías para enfermedades crónicas específicas frecuentemente nombradas por los informantes como "reuma" y "diabetes" y se agruparon usos generales de acuerdo a categorías establecidas por los propios informantes que coincidían para todos los sitios, como lo son las especies de usos "refrescantes", "cicatrizantes" y "sedantes". Se incluyó la categoría "vitamínicos" en el sitio Los Manantiales, ya que varios informantes nombraron esta categoría para ciertas especies que son utilizadas con este fin. Además, se constituyó la categoría "otros", que agrupa aquéllas especies de usos diversos que no tienen relación entre ellos, pero que por ser mencionadas sólo una vez, no pueden ser agrupadas en una categoría propia (Fig. 3).

La mayor proporción de las plantas se utiliza para el tratamiento de afecciones relacionadas con el sistema digestivo en todos los sitios de estudio (32-41\%; Fig. 3). Entre las afecciones tratadas con este grupo de especies se incluyen aquellas específicas para "problemas de hígado" y para "el empacho"; esta última dolencia, según los informantes de Los Manantiales, debe tratarse combinando un procedimiento relacionado con el ámbito de lo mágico, que se llama "medir el empacho", con el uso de algunas, especies medicinales que se ingieren en forma de infusión. Siguen en abundancia aquellas especies utilizadas para el tratamiento de afecciones del sistema respiratorio (13-26\%), luego las utilizadas para afecciones del sistema circulatorio, incluyendo aquí las especies denominadas "depurativas de la sangre", presentando algunas propiedades diuréticas. Se incluyen en esta categoría porque los informantes las relacionaron con enfermedades propias de la

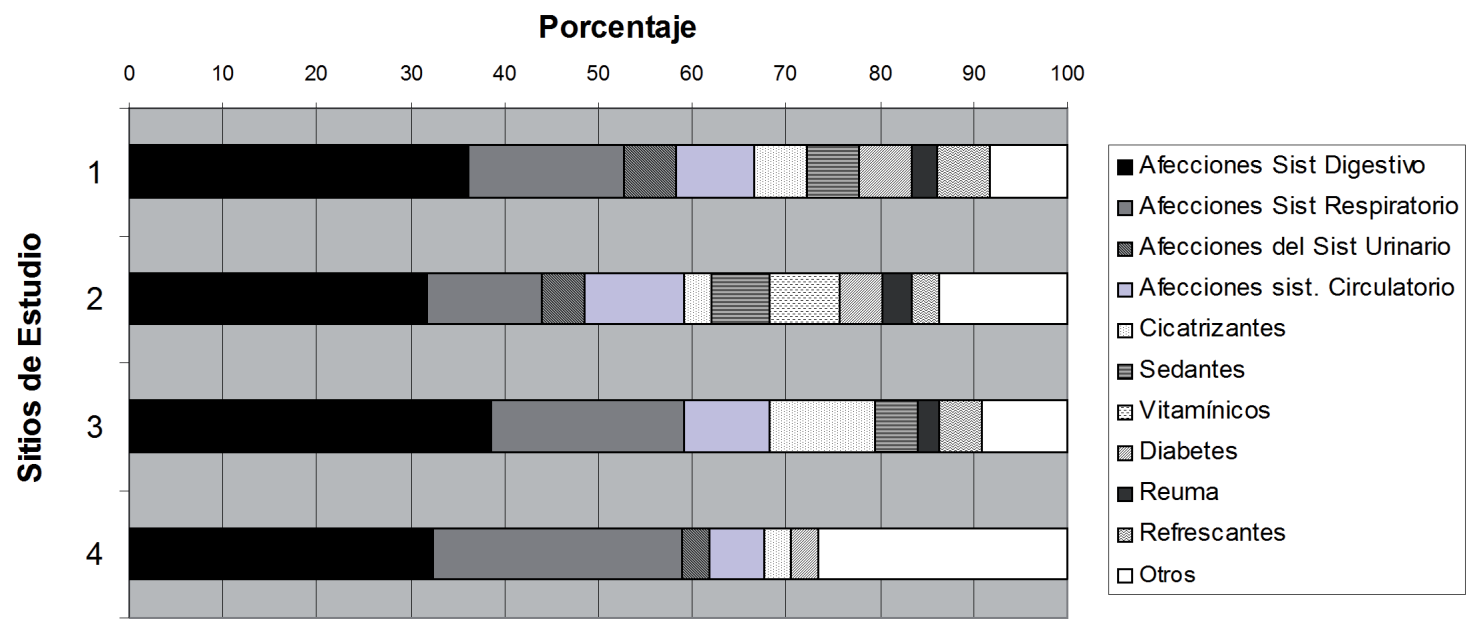

Fig. 3. Afecciones tratadas con especies medicinales en cuatro sitios de estudio del Bosque Chaqueño Serrano de Córdoba, Argentina. En el eje y se muestran los sitios de estudio: (1) La Rancherita; (2) Los Manantiales; (3) Santo Domingo; (4) Falda del Carmen. En el eje $x$ los porcentajes encontrados para cada una de las categorías de plantas medicinales. 
sangre, por ejemplo, tener "sangre gruesa", dolencia popular que se trata con "sanguinaria" (Cuphea glutinosa, mencionada en Falda del Carmen). El porcentaje de especies usadas para las afecciones del sistema circulatorio varió entre el 6-10\%. En Santo Domingo, se encontró que son muy utilizadas las especies para cicatrización de heridas (11\%).

Es interesante mencionar que en el sitio Los Manantiales la categoría "vitamínicos" está representada con un 7\% de las especies, a diferencia del resto de los sitios donde esta categoría no tuvo menciones. Aquí, se incluyen especies que los informantes consideran importantes para prevenir enfermedades, ya que aportan gran cantidad de vitaminas al organismo, algunos ejemplos son: zanahoria (Daucus carota), brócoli (Brassica oleracea) y espinaca (Spinacea oleracea). Las mismas se preparan licuadas y se consumen en forma de "jugo" junto con semillas tales como girasol (Helianthus annuus) y almendras (Prunus amygdalus). Según los informantes, de esta manera sus principios se encuentran "potenciados" y, por ello, son más efectivos.

Algunas de las especies conocidas se relacionan con el ámbito de lo mágico, con la regulación del ciclo menstrual, especies abortivas y específicas para tratar la impotencia. Estas especies son mencionadas por los informantes en todos los sitios (Tabla 5), pero ninguno de ellos hace referencia a su uso efectivo en la actualidad. Por ser temáticas consideradas tabú en nuestra sociedad, es muy probable que muchas de las especies mencionadas se utilicen con frecuencia en el ámbito familiar, manteniéndose ocultas para el ámbito público. En cuanto a las especies propias para las mujeres, los conocimientos más amplios se presentan en el sitio Los Manantiales. Entre las especies mencionadas se incluyen galactógenas, reguladoras del ciclo menstrual, abortivas y una en particular que se utiliza para la eliminación de la placenta, en los casos en que esto no sucede naturalmente. Sin embargo, en este sitio no se menciona ninguna especie indicada para los varones. En contraposición, en el sitio Santo Domingo, la única especie mencionada es indicada para el sexo masculino. Del conjunto de especies, la más ampliamente conocida es la "doradilla" (Anemia tomentosa), a la cual se le atribuyen propiedades relacionadas a la regulación del ciclo menstrual.

Tabla 5. Especies medicinales mágicas, relacionadas con la reproducción y adicciones en cuatro sitios de estudio del Bosque Chaqueño Serrano de Córdoba, Argentina. Se incluye nombre científico, nombres vulgares, usos y sitios donde fueron mencionadas. Las siglas indican LR: La Rancherita, LM: Los Manantiales, SD: Santo Domingo, FDC: Falda del Carmen.

\begin{tabular}{|c|c|c|c|}
\hline Nombre científico & Nombres vulgares & Usos & $\begin{array}{l}\text { Sitios donde fueron } \\
\text { mencionadas }\end{array}$ \\
\hline Huperzia saururus (Lam) Trevis. & Cola de quirquincho & Impotencia & LR, SD \\
\hline Anemia tomentosa (Savigny) Sw. & Doradilla & $\begin{array}{l}\text { Regulador del ciclo } \\
\text { menstrual }\end{array}$ & LR, LM, FDC \\
\hline Artemisia vulgaris L. & Altamisa, Artemisa & $\begin{array}{l}\text { Regulador del ciclo } \\
\text { menstrual }\end{array}$ & LM \\
\hline Adiantum spp. & Culandrillo & Abortiva & LM \\
\hline Schinus areira L. & Guareguay, Aguaribay & Abortiva & LM \\
\hline Especie indeterminada & Helecho macho, Calaguala & Abortiva & LM \\
\hline $\begin{array}{l}\text { Tripodanthus flagellaris (Cliam. \& } \\
\text { Schlecht.) Tiegh. }\end{array}$ & Liguilla & $\begin{array}{l}\text { Eliminación de la } \\
\text { placenta }\end{array}$ & LM \\
\hline $\begin{array}{l}\text { Morrenia odorata (Hook. \& Arn.) } \\
\text { Lindl. }\end{array}$ & Tasi & Galactógena & LM \\
\hline Ruta graveolens $\mathrm{L}$. & Ruda & Sahúmo de la casa & LM \\
\hline Trixis divaricata (Kunth) Spreng. & Contra yerba & Sahúmo de la casa & LM \\
\hline $\begin{array}{l}\text { Jodina rhombifolia (Hook. \& } \\
\text { Arn.) Reissek }\end{array}$ & Sombra de toro & Alcoholismo & LM, FDC \\
\hline Salix humboldtiana Willd. & Sauce & Brindar energía & SD \\
\hline
\end{tabular}


En cuanto a las plantas relacionadas con el ámbito de lo mágico, sólo se mencionan en el sitio Los Manantiales. La "contra yerba" (Trixis divaricata) se indica para limpiar la casa de dos maneras posibles. Una, a través del "sahúmo", que implica quemar las ramas de esta especie dentro de la casa a limpiar, recorriendo cada uno de los rincones de la misma con las ramas encendidas. Se recomienda abrir todas las ventanas cuando se realiza esta acción. La otra modalidad consiste en rociar la casa por dentro con agua de hervor de "contra yerba". En este caso, se recomienda particularmente rociar dentro de los armarios y debajo de las camas. En cambio, para la utilización de la "ruda", no se mencionan indicaciones específicas.

Una especie de particular uso es la "sombra de toro" (Jodina rhombifolia) que se recomienda para la curación del alcoholismo. Uno de los informantes de la localidad de Falda del Carmen explicaba: "Dicen que si haces la maceración esa (frutos de sombra de toro que se dejan remojando varios días en agua) y se la mezclás en el vino que toma el alcohólico, va dejando de tomar. En cuatro meses te garantizan que el tipo no chupa más". Lo interesante de esta afirmación, además del tiempo exacto necesario para la recuperación de la enfermedad, es que presupone que la persona alcohólica es del sexo masculino; para la cita de esta misma especie en Los Manantiales, se supone lo mismo. Por último, se menciona al "sauce" (Salix humboldtiana) como capaz de brindar "buenas energías". E1 informante recomienda que "cuando uno está medio tristón, así, deprimido... te sentás abajo del sauce y te recupera la energía".

\section{Discusión}

\section{EI sistema etnomédico}

Actualmente en la Argentina, la población, tanto campesina como urbana, atiende su salud a través de un sistema etnomédico que traslapa la biomedicina, las medicinas tradicionales y el autotratamiento. Además, en ocasiones se suman las medicinas religiosas y alternativas (Idoyaga Molina, 1997). La selección y combinación de estos componentes depende de las diferencias étnicas, sociales y culturales de la población (Idoyaga Molina, 1999). Esta combinación de prácticas y saberes se ve representada de maneras variadas en las comunidades bajo estudio. En los sitios Los Manantiales y Santo Domingo se observa una mayor preponderancia de tratamientos relacionados con medicinas alternativas. Un ejemplo de ello son los conocimientos de los informantes relacionados con la preparación de remedios homeopáticos, tratamientos naturistas, "iriología" y "diestecia" en el caso de Los Manantiales, y la utilización de técnicas de la "biodinámica para la producción agropecuaria", así como conocimientos sobre "medicina antroposófica" en el sitio Santo Domingo. Una característica particular a destacar es que, tanto en Los Manantiales como en Santo Domingo, una gran proporción de los entrevistados recurre a bibliografía especializada para nutrir sus conocimientos acerca de plantas medicinales.

Para dar cuenta de ello, se transcriben algunos recortes de las entrevistas. Por ejemplo, en los Manantiales, uno de los informantes me contaba: "La verdolaga, se come. La bardana misma, tiene propiedades medicinales. No me acuerdo donde leí eso... cuando estaba estudiando agricultura biológico-dinámica, Steiner la mencionaba mucho a la bardana. Se que tiene muchas propiedades yanguinizantes. Tiene muchas vitaminas, es vitamínico constructiva, la raíz de la bardana" En Santo Domingo me decían: I:"La ortiga es una depuradora de la sangre impresionante, como toda depuradora te limpia de acido úrico, de colesterol, de azúcar. Te elimina todo lo nocivo del cuerpo. Aparte aporta hierro y calcio de altísima calidad. Por eso se utiliza muchísimo para las anemias. Y además por ser diurética es muy buena para las infecciones de las vías urinarias. Vejiga, riñones, todo eso. Además es tintórea y da un color verde muy profundo.

E: ¿Esa la cultivas vos?

I: La traje, esta es introducida. Urtica dioica es. No, y bueno. Esta forma parte de las plantas de la agricultura biodinámica. No se si conoces algo de eso...Y fui recopilando de la bibliografía que yo tengo. Acá tengo el listado de las plantas, algunas cultivadas y otras nativas". 
En La Rancherita y Falda del Carmen, los conocimientos de los informantes se basan en la biomedicina (sistema público de salud), medicinas tradicionales y caseras, además de estar sustentados en la transmisión oral por parte de antepasados expertos en la temática o en la transmisión oral horizontal entre los miembros de la misma comunidad. Esto se ve reflejado en los comentarios sobre tiempos e historias pasadas, a lo largo de las entrevistas. Por ejemplo en La Rancherita comentaban entre dos informantes: "En tiempo nuestro no había remedios, o había pero uno no tenia en el campo, entonces se usaban yuyos, todo era té, la vieja nos daba yuyos." Otro informante del mismo sitio explicaba "Eso me sabía dar mi abuela, que son esos remedios del campo que son muy buenos" en Falda del Carmen respecto a una planta en particular "Después el chañar se le saca el fruto o la cascarita, se hace hervir con la cascarita. Eso es muy bueno para el pecho. Si me habrá dado mi mamá para cuando estábamos con catarro. Yo sufría mucho del pecho. Antes era todo mas sano. Porque la gente duraba más, también."

\section{Sobre la diversidad de conocimientos}

Al comienzo de esta investigación se postuló que la cercanía de los pobladores a ANP se relacionaría con un mayor conocimiento sobre plantas medicinales por una mayor disponibilidad ambiental de recursos. De acuerdo con Benz \& al. (2000) se pensó que el acceso continuo al bosque y el uso de sus recursos podría estimular a los pobladores locales a conservar los conocimientos y saberes tradicionales. Por ello, se consideró que las comunidades cercanas a ANP podrían presentar ventajas respecto a las comunidades lejanas a las mismas, en cuanto a la posibilidad de mantenimiento de los conocimientos a lo largo del tiempo. Sin embargo, no se encontró una relación clara, ya que no se observaron diferencias en la riqueza de conocimientos entre sitios cercanos y lejanos a ANP. Por ejemplo, la mayor riqueza de conocimientos se observó en los sitios Los Manantiales (cercano a ANP) y Santo Domingo (lejano a ANP), donde una gran parte de las especies conocidas son de origen exótico y no se encuentran en los relevamientos realizados en el bosque nativo. El conocimiento de varias de las especies podría explicarse porque son cultivadas por los pobladores entrevistados o por su aparición espontánea en los sectores peri-domiciliarios.

Para el caso de la diversidad de conocimientos, tampoco se advierten diferencias entre las especies relevadas y las especies conocidas por los pobladores entre los distintos sitios. De todas maneras, es interesante destacar que, para todos los sitios, el índice de diversidad obtenido para las especies conocidas es mayor que para las especies medicinales relevadas. Esto puede deberse al enriquecimiento de los conocimientos de la flora local con conocimientos de especies exóticas, en especial, plantas de origen europeo. En este sentido, las fuentes de conocimiento del sistema etnomédico de esta región, recibieron aportes de los españoles durante la conquista y de inmigrantes europeos a finales del siglo XIX y principios del siglo XX (Idoyaga Molina, 2001).

En coincidencia con Begossi (1996) y Arias Toledo \& al. (2007 a,b), los valores del índice de Shannon que se obtuvieron para las especies medicinales conocidas en los cuatro sitios de estudio resultaron cercanos a aquellos encontrados para diferentes comunidades del mundo y, en particular, para comunidades de la misma región biogeográfica. Según Begossi (1996) la utilización de los índices de diversidad nos ayuda a visualizar aspectos relacionados con la homogeneidad/heterogeneidad del uso de plantas dentro de una comunidad. Es decir, los índices de diversidad de especies conocidas podrían representar una alta diversidad de conocimientos.

Tampoco se encontraron diferencias en la similitud entre especies relevadas y conocidas entre sitios cercanos y lejanos a ANP, ni cuando se comparan especies conocidas entre sí. Se considera que esta baja similitud puede deberse a varios factores; entre ellos, se puede destacar que las especies más abundantes en el terreno no son utilizadas o reconocidas como medicinales, mientras que muchas de las especies conocidas por los informantes ocurren en baja abundancia. Además, según 
la información brindada por los entrevistados, muchas de ellas presentan una distribución circunscripta a áreas específicas pequeñas, son especies exóticas que no se encuentran en el área o se trata de especies cultivadas en el área perimetral de las viviendas.

\section{Los conocimientos discriminados según el estatus de las especies}

Los conocimientos y la utilización de especies medicinales nativas no estuvieron significativamente relacionados con las comunidades cercanas a ANP, aunque estas comunidades presentan mayor accesibilidad a especies nativas presentes en los fragmentos de bosque. Los sitios con mayores conocimientos y mayor porcentaje de utilización de especies medicinales nativas fueron La Rancherita (cercano a ANP) y Falda del Carmen (lejano a ANP). Mientras que tanto en Los Manantiales como en Santo Domingo hay una mayor preponderancia de conocimientos sobre especies medicinales exóticas. El perfil más urbano de estas dos comunidades probablemente influya sobre estos conocimientos. Como sugieren Rocha Silva \& Andrade (2005) para la Zona de Litoral del Estado de Pernambuco, Brasil, los altos valores de conocimiento de especies exóticas pueden indicar un proceso de sustitución de los recursos vegetales nativos por aquellos más difundidos en la sociedad en general. En su estudio, las especies más citadas en cada comunidad son en su mayoría cultivadas, lo que para ellos demuestra la importancia que estas plantas vienen adquiriendo en detrimento de las nativas. Sin embargo, en las comunidades de Córdoba estudiadas en este trabajo, las especies más conocidas son nativas. El mayor conocimiento de especies exóticas en Los Manatiales y Santo Domingo, podría estar relacionado con el hecho de que las fuentes de consulta de conocimientos sobre las plantas son libros, en su mayor parte de especies medicinales foráneas.

\section{Usos de las plantas medicinales}

Las enfermedades tratadas a través de la utilización de plantas medicinales en los cuatro sitios de estudio corresponderían a desequilibrios orgánicos explicados por causas naturales, de acuerdo a la clasificación propuesta por Idoyaga Molina (2000).

En coincidencia con lo encontrado por Arias Toledo (2006) para la localidad de Cerro Colorado, en los cuatro sitios estudiados la mayor proporción de las especies se utilizan para tratar afecciones relacionadas con el sistema digestivo. Según Arias Toledo (2006) y Scarpa (2002), la alta frecuencia de afecciones del aparato digestivo podría estar relacionada con la dieta altamente proteica de los criollos de la región chaqueña nor-occidental, y podría hacerse extensivo para este caso.

Respecto a los usos relacionados con el ámbito de lo mágico, cabe destacar que el origen de las prácticas que se mencionan anteriormente remite, según Idoyaga Molina \& Romero (2008), al catolicismo, en cuanto a sistema de creencias. Entre estas prácticas, pueden figurar la invocación y el rezo, repetición de la señal de la cruz, lavado purificatorio y sahumado de pacientes y espacios, entre otros. La acción de sahumar sirve para curar al doliente, restaurar el ambiente o alejar las emanaciones negativas de los objetos, animales o cualquier pertenencia que se pretenda resguardar (Idoyaga Molina \& Romero, 2008). En el caso estudiado en el presente trabajo, el sahumado de personas, casas u otros bienes cumple con una función preventiva y terapéutica.

\section{Conclusiones}

Todo lo descrito anteriormente sugiere que existirían otros factores que influyen sobre los conocimientos y la utilización de plantas medicinales, que no tienen que ver con la cercanía a ANP y/o la disponibilidad ambiental de las plantas medicinales. Entre aquellos factores, que podrán considerarse en futuros estudios, se puede mencionar el intercambio constante de saberes y de especies entre los informantes. En concordancia con lo encontrado en las Yungas de la Argentina por Hilgert \& Gil (2008), las comunidades estudiadas resuelven el aprovisionamiento de plantas medicinales no sólo con aquellas que 
pueden encontrar en el terreno, sino también con otros medios de intercambio y compra.

El universo de conocimientos sobre plantas medicinales va más allá de las especies que pueden ser encontradas, ya sea en los sitios lejanos como cercanos a ANP. De esta manera, aunque las especies no se encuentren en la zona, los conocimientos se mantienen y se enriquecen constantemente, aportando a la memoria colectiva de cada una de las comunidades estudiadas, formando parte del entramado cultural (Trillo \& al., 2010).

Se espera realizar, entonces, nuevos estudios enfocados en el flujo de información y el intercambio de especies que los informantes realizan con la comunidad en general, y con otros informantes, dentro de la misma comunidad o fuera de ella, centrando las investigaciones en las redes de conocimientos entre los pobladores de estas comunidades. Para ello, se requiere explorar los mecanismos culturales de mantenimiento de la tradición, analizar los procesos de transmisión y supervivencia del conocimiento para estas cuatro comunidades, como proponen algunos autores (Hilgert \& Gil, 2008, Trillo \& al., 2010).

\section{Agradecimientos}

Se agradece a dos revisores anónimos por las sugerencias realizadas a una versión anterior de este trabajo. A todos los informantes cuyos valiosos conocimientos y buena disposición permitieron la realización de este trabajo. A las autoridades y personal de la comuna de La Rancherita, de la estancia Santo Domingo y la Reserva Los Manantiales por su apoyo en el trabajo de campo al permitirnos utilizar distintos sitios de bosque. A Gabriela Ferreiro por sus aportes. A Norma Hilgert por la lectura cuidadosa del texto original y por sus sugerencias para enriquecerlo. Finalmente, agradecemos al Consejo Nacional de Investigaciones Científicas y Técnicas (CONICET), Agencia Nacional de Promoción Científica y Tecnológica y a la Secretaría de Ciencia y Tecnología de la Universidad Nacional de Córdoba por el financiamiento recibido.

\section{Bibliografía}

ALBUQUERQUE, U. P., R. LUCENA \& L. CRUZ DA CUNHA. 2008. Métodos e técnicas na pesquisa etnobotânica. Comunigraf Editora, Recife. 322 pp.

ARIAS TOLEDO, B. 2006. Aspectos cuantitativos, cualitativos y simbólicos de la medicina tradicional de los pobladores de Cerro Colorado (Córdoba, Argentina) PINACO-Investigaciones sobre Antropología Cognitiva IV: 105-115.

2008. Disponibilidad y uso de las plantas silvestres alimenticias y medicinales en las sierras de Córdoba: su asociación con factores fitogeográficos y culturales, Tesis de Doctorado. Facultad de Ciencias Exactas, Físicas y Naturales, Universidad Nacional de Córdoba, Córdoba. 147 pp.

, L. GALETTO \& S. COLANTONIO. 2007a. Knowledge and use of edible and medicinal plants in two populations from the Chaco Forest, Córdoba province, Argentina. J. Ethnobiol. 27: 218-232.

2007b. Uso de plantas medicinales y alimenticias según características socioculturales en Villa Los Aromos. Kurtziana 33: 79-88.

BARBOZA, G., J. J. CANTERO, C. NUÑEZ \& L. ARIZA ESPINAR. 2006. Flora Medicinal de la Provincia de Córdoba (Argentina). Pteridófitas y Antófitas silvestres o naturalizadas. Museo Botánico Córdoba, Universidad Nacional de Córdoba, Córdoba. $1250 \mathrm{pp}$.

BARBOZA, G., J. J. CANTERO, C. NUÑEZ, A. PACCIARONI \& L. ARIZA ESPINAR. 2009. Medicinal plants: A general review and a phytochemical and ethnopharmacological screening of the native Argentine Flora. Kurtziana 34: 7-365.

BEGOSSI, A. 1996. Use of ecological methods in ethnobotany: Diversity indices. Econ. Bot. 50: 280-289.

BENZ, B. F., J. CEVALlos, E. F. SANTANA, M. J. ROSALES, \& M. GRAF. 2000. Losing knowledge about plant use in the Sierra Manantlan Biosphere Reserve, Mexico. Econ. Bot. 54: 183-191.

CABALLERO, J. 1986. Etnobotánica y desarrollo: la búsqueda de nuevos recursos vegetales. Memorias del IV Congreso Latinoamericano de Botánica, Simposio de Etnobotánica, pp. 79-96. Editorial Guadalupe, Bogotá.

—— \& L. CORTÉS. 2001. Percepción, uso y manejo tradicional de los recursos vegetales en México. En: B. Rendón Aguilar; S. Rebollar Domínguez; J. Caballero Nieto; M. A. Martínez Alfaro (eds.), Plantas, cultura y sociedad. Estudio sobre la relación entre seres humanos y plantas en los albores del siglo XXI. pp. 79-101. Editorial Universidad Autónoma Metropolitana, México DF.

CABRERA, A. L. 1976. Regiones Fitogeográficas Argentinas. Enc. Argent. Agric. Jard. II (1): 1-85. 
Acme, Buenos Aires.

FEINSINGER, P. 2003. El diseño de estudios de campo para la conservación de la biodiversidad. Editorial FAN, Santa Cruz de la Sierra. 161 pp.

GUBER, R. 1991. El Salvaje Metropolitano. Colección Comunicación y sociedad. Editorial Legasa. Buenos Aires. 220 pp.

HANAZAKI, N., J. TAMASHIRO, H. LEITAO-FILHO \& A. BEGOSSI. 2000. Diversity of plant uses in two Caiçara communities from the Atlantic Forest coast, Brazil. Biodiversity and Conservation 9: 597-615.

HILGERT, N. \& G. E. GIL. 2008. Los cambios de uso del ambiente y la medicina herbolaria. Estudio de caso en Yungas Argentinas. Bol. Lationoamer. Caribe Plant. MedicAromát. 7: 130-140.

IDOYAGA MOLINA, A. 1997. Ethnomedicine and world-view. A comparative analyzis of the rejection and incorporation of the contraceptive methods among argentine women. Anthropology and Medicine 4: 145-158.

. 1999. La selección y combinación de medicinas entre la población campesina de San Juan (Argentina). Scripta Ethnologica 21: 7-33.

2000. Natural and Mythical explanations. Reflections on the taxonomies of disease in Northwestern Argentina. Acta Americana 8: 17-32.

- 2001. Etiologías, síntomas y eficacia terapéutica. El proceso diagnóstico de la enfermedad en el Noroeste argentino y Cuyo. Mitológicas 16: 9-43.

— \& F. S. ROMERO. 2008. Daño, terapéutica ritual y manipulación de lo sagrado en las medicinas tradicionales del noroeste argentino. Ciencias Sociales y Religión 10: 137-158.

INDEC. 2001. Censo Población. Instituto Nacional de Estadísticas y Censos. Buenos Aires. Disponible en: http://www.indec.gov.ar/

INSTITUTO DE BOTÁNICA DARWINION. 2011. Base de datos. Flora del Cono Sur. Disponible en: http://www2.darwin.edu.ar/, Consultado 7.10.2011.

MARTÍNEZ, P. H. \& A. FIERRO. 2001. El comercio de plantas medicinales: algunos rasgos significativos en el centro de México. En: B. Rendón Aguilar; S. Rebollar Domínguez; J. Caballero Nieto; M. A. Martínez Alfaro (eds.), Plantas, cultura y sociedad. Estudio sobre la relación entre seres humanos y plantas en los albores del siglo XXI. pp. 53-75. Editorial Universidad Autónoma Metropolitana, México.

MARTÍNEZ, G. J. 2005. Recolección y comercialización de plantas medicinales en el Departamento Santa María, Provincia de Córdoba, Argentina. Acta Farm. Bonaerense 24: 575-584.

MENSEGUEZ, P., L. GALETTO \& A. M. ANTON. 2007. El uso de plantas medicinales en la población campesina de El Puesto (Córdoba, Argentina). Kurtziana 33: 89-102.

ROCHA SILVA, A. J. \& L. H. ANDRADE. 2005. Etnobotânica nordestina: estudo comparativo da relaçao entre comunidades e vegetaçao na Zona do Litoral- Mata do Estado de Pernambuco, Brasil. Acta Bot. Bras. 19: 45-60.

SCARPA, G. 2002. Plantas empleadas contra trastornos digestivos en la medicina tradicional criolla del Chaco noroccidental. Dominguezia 18: 36-50.

TAYLOR S. J. \& R. BOGDAN. 1987. Introducción a los Métodos Cualitativos de Investigación. Editorial Paidós, Buenos Aires. 345 pp.

TRILLO, C., P. DEMAIO, S. COLANTONIO \& L. GALETTO. 2007. Conocimiento actual de plantas tintóreas por los pobladores del valle de Guasapampa, Provincia de Córdoba. Kurtziana 33: 65-71.

TRILLO, C., B. ARIAS TOLEDO, L. GALETTO \& S. COLANTONIO. 2010. Persistence of the use of medicinal plants in rural communities of the western Arid Chaco (Córdoba, Argentina). The Open Complementary Medicine Journal 2: 80-89.

ZAK, M., M. R. CABIDO \& J. HODGSON. 2004. Do subtropical seasonal forests in the Gran Chaco, Argentina, have a future? Biological Conservation 120: 589-598.

Original recibido el 12 de septiembre de 2011; aceptado el 20 de noviembre de 2011. 


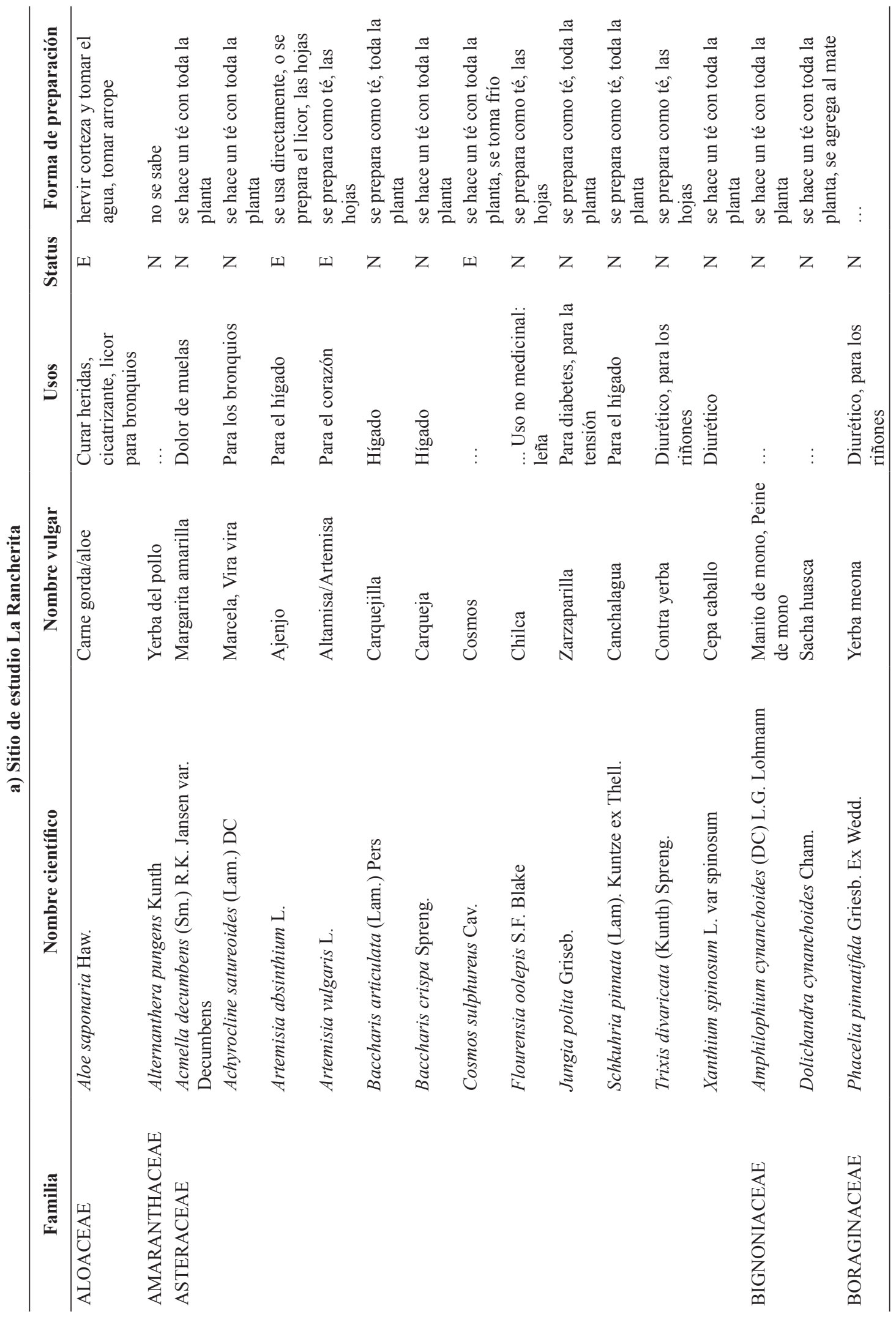




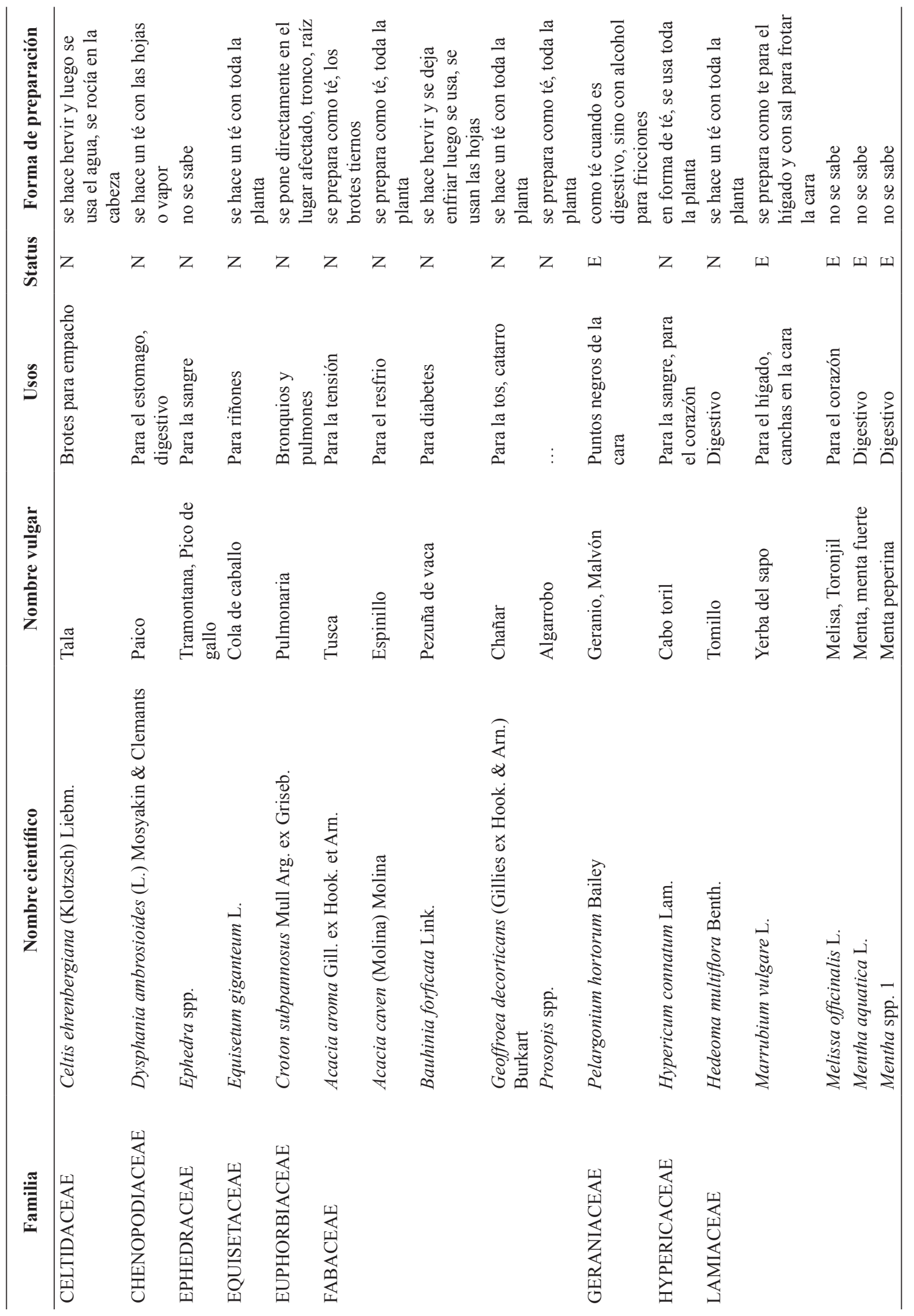




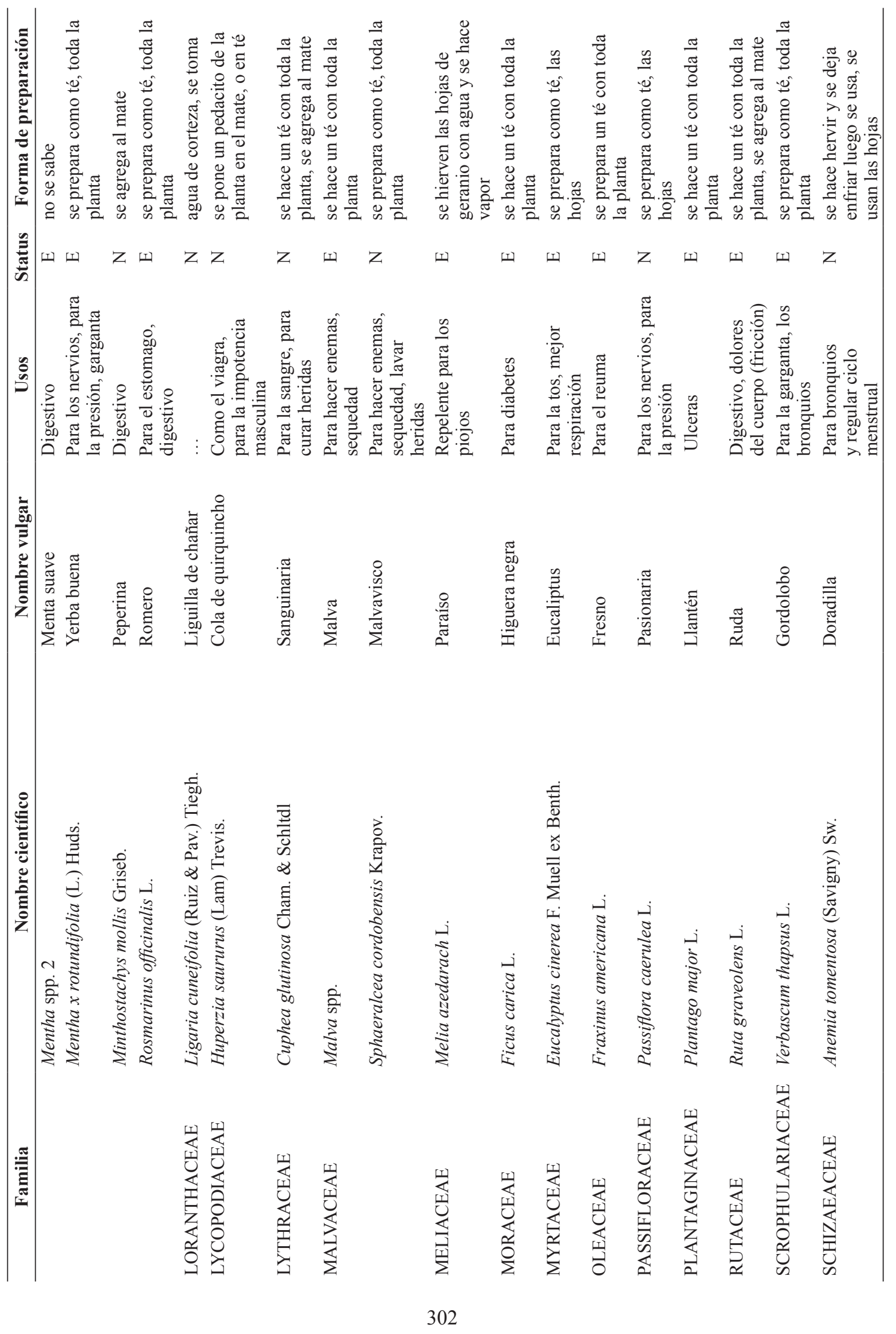


V. Furlan \& al., Conocimiento y utilización de plantas medicinales por pobladores rurales de Córdoba
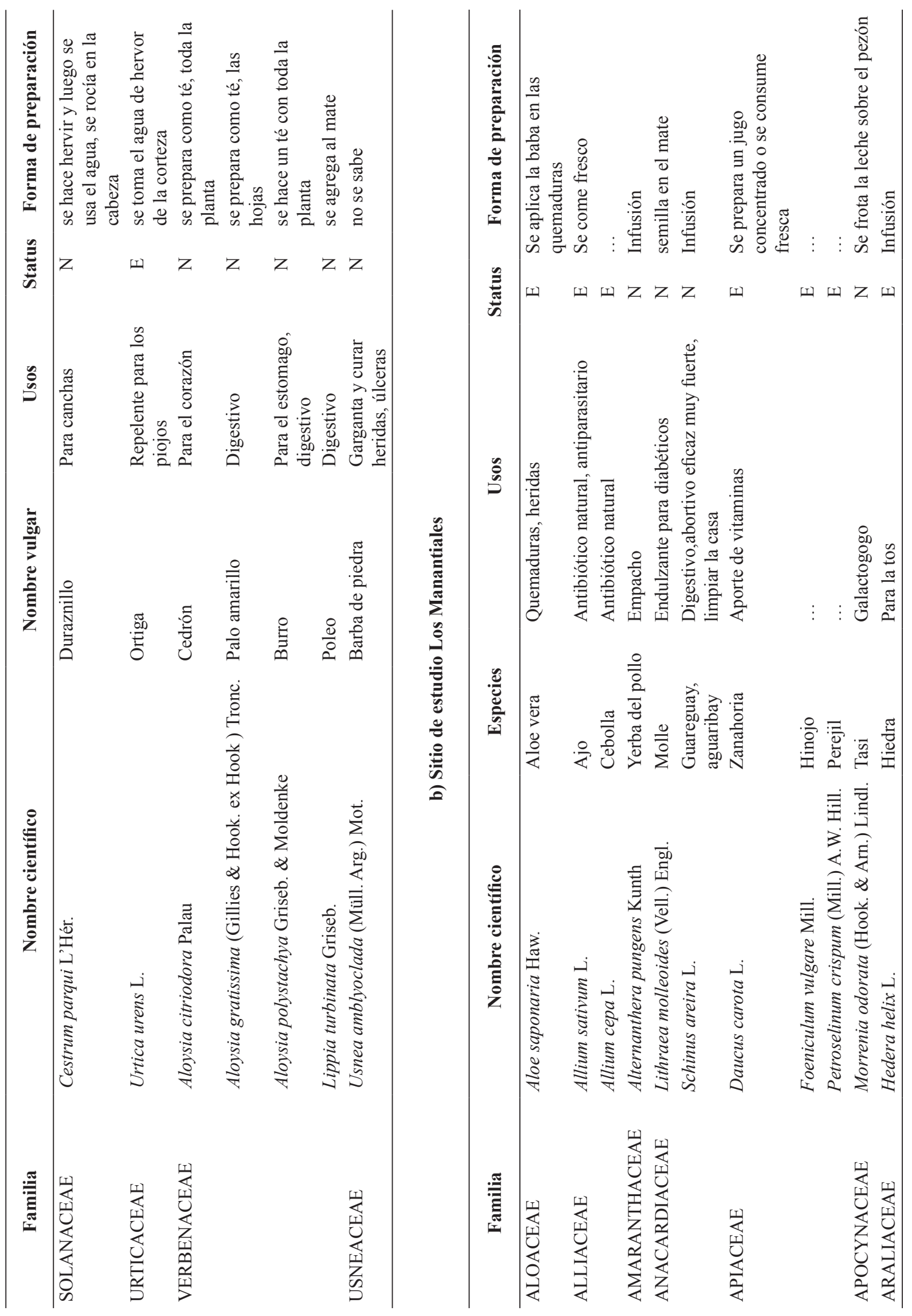
BONPLANDIA 20(2). 2011

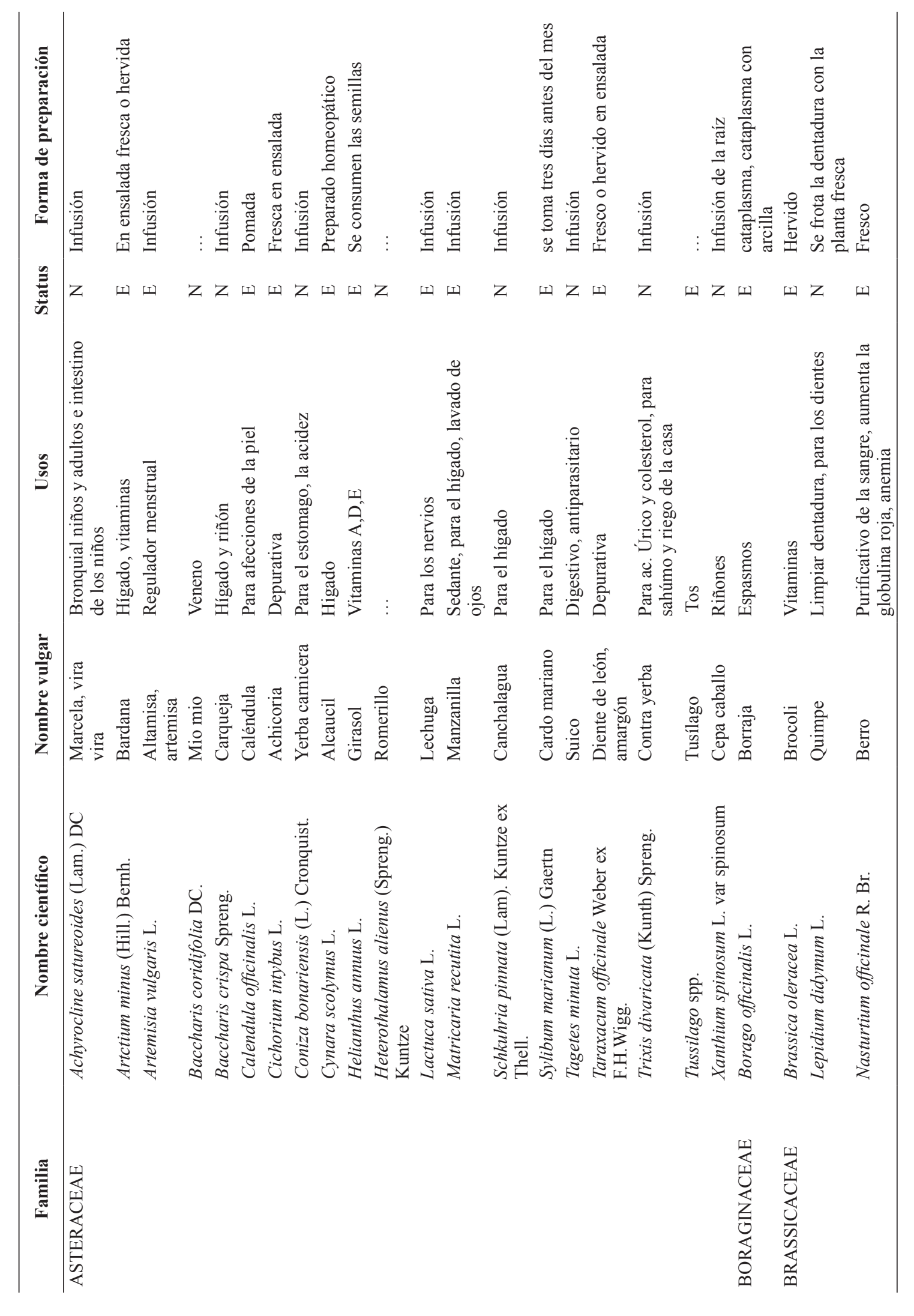




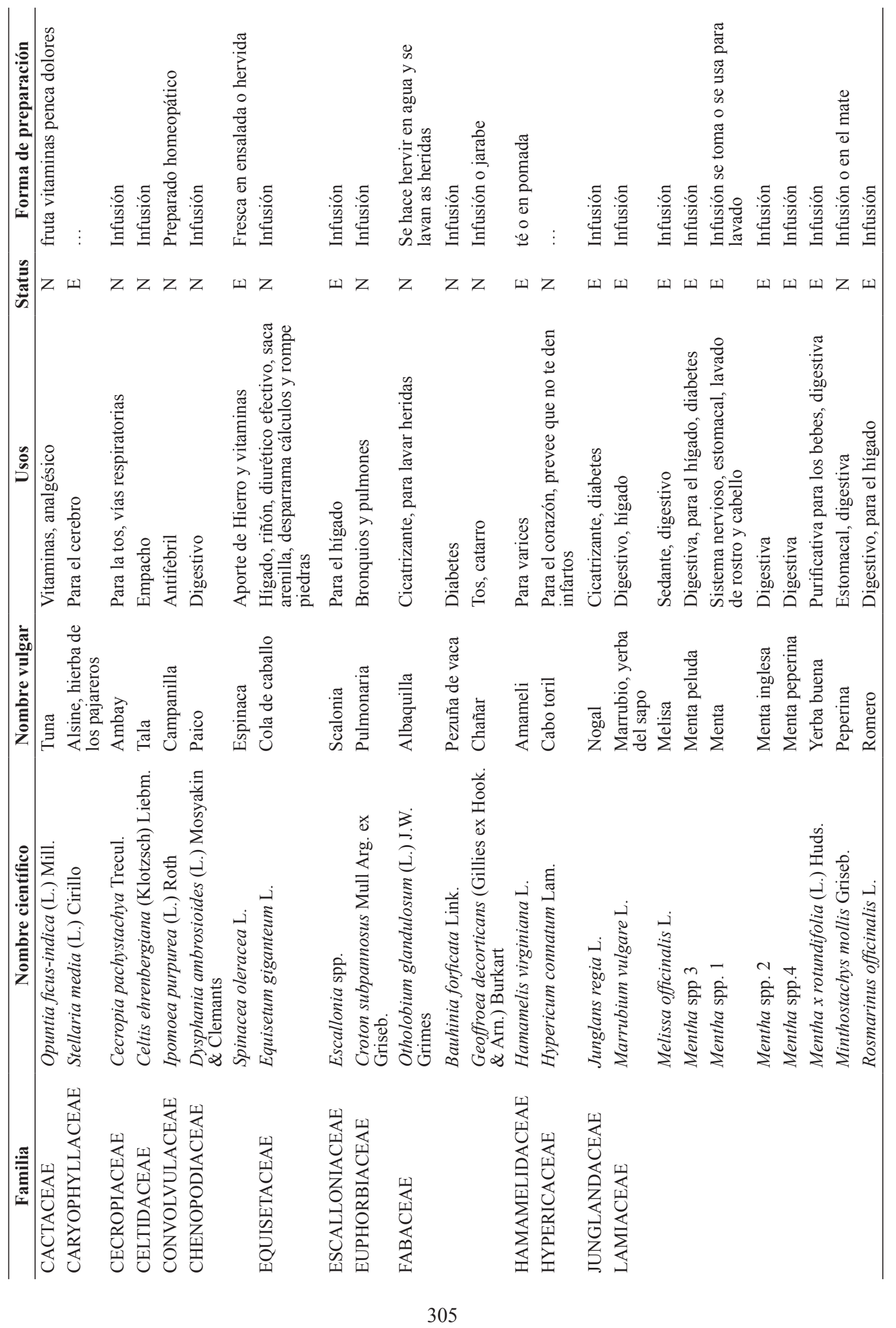


BONPLANDIA 20(2). 2011

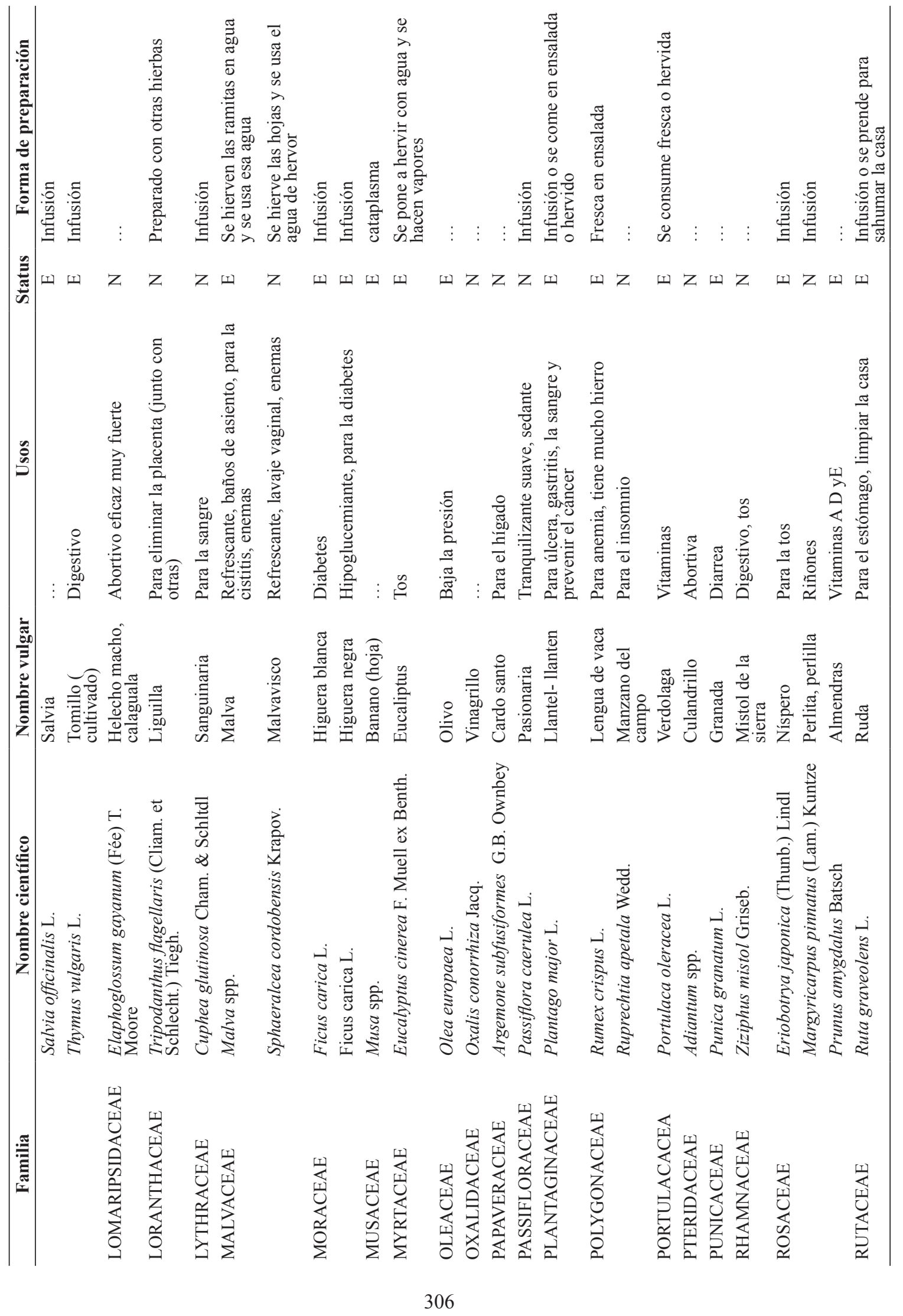


V. Furlan \& al., Conocimiento y utilización de plantas medicinales por pobladores rurales de Córdoba

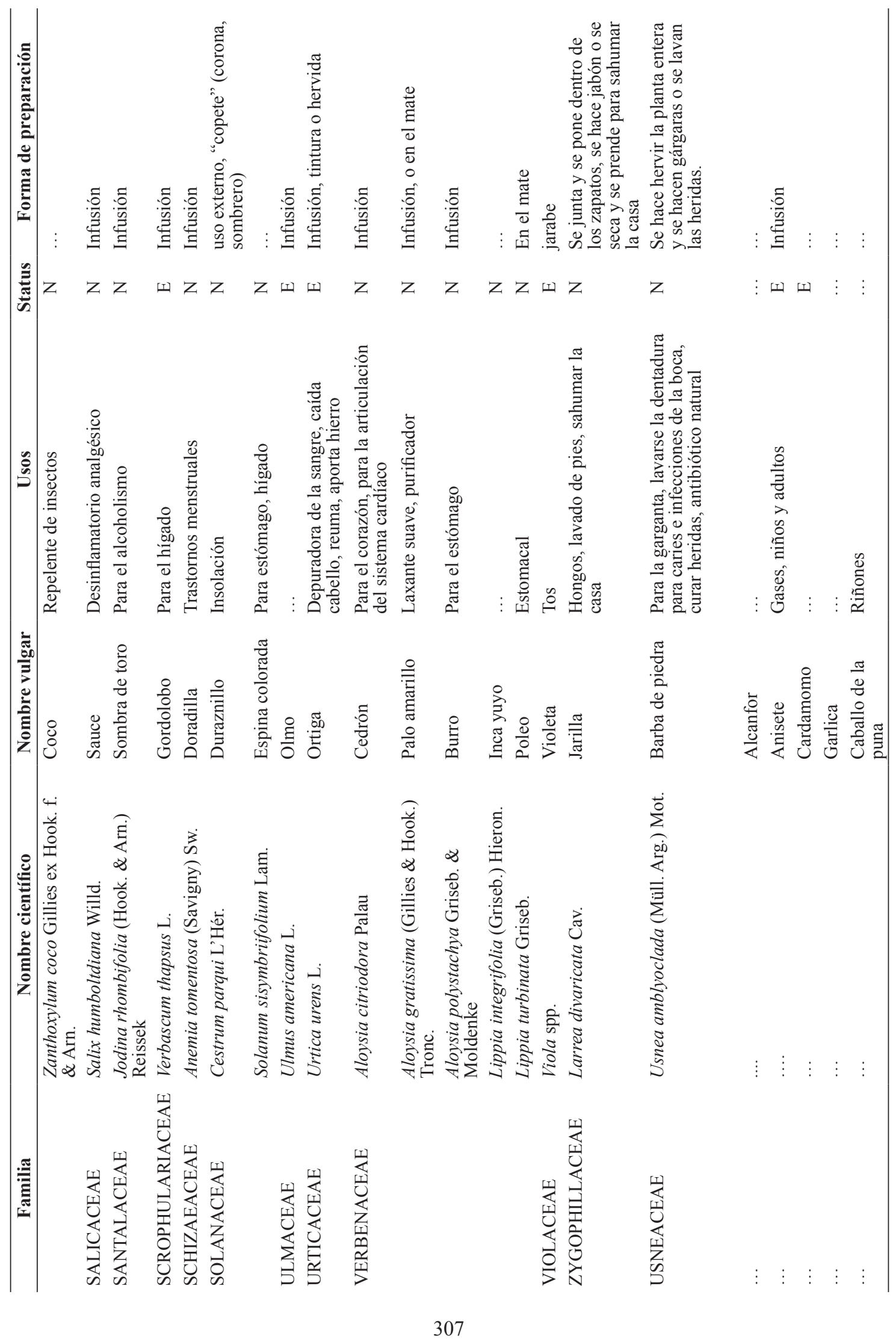


